R E V I S T A D E E S T U D I O S I N T E F N A C I O NA L E S

\title{
La Vieja y la Joven Guardias: la Autoridad Palestina y el proceso de paz en la encrucijada
}

\author{
Khalil Shikaki
}

\begin{abstract}
El trabajo, que analiza la estructura de poder de la Autoridad Palestina (AP), revela la existencia de un profunda contradicción entre los líderes palestinos formados en la lucha exterior y los más jóvenes, llevados a desenipeñar tareas de conducción y gestión al interior del territorio. Dentro de esta contradicción, la primera intifada aparece como elemento catalizador que consolidó dos dinámicas significativas en la política y' la sociedad palestinas.

A través de las cifras que ofrece el autor, se puede percibir claramente la delicada correlación de fuerzas entre las que denonina Vieja y Joven Guardias, y entre ambas y los elementos más militantes del islamismo y el nacionalismo exterior a la AP. Al pasar revista a las distintas posibilidades de arreglo, se privilegia el análisis de la retirada unilateral de Israel de los territorios ocupados. En todo caso, el único mensaje claro que se desprende de la profunda insatisfacción de la opinión pública palestina respecto de la AP e incluso de Arafat, es que hay que reformarse o desaparecer:
\end{abstract}

Podría ser que, desde septiembre de 2000, Yasser Arafat y la Autoridad Palestina (AP) hayan instrumentado y conducido la intifada de manera de debilitar y humillar a Israel, obligándolo a aceptar exigencias desproporcionadas de solución política? Como consecuencia de ello, ¿han aumentado la legitimidad y la autoridad suya y de la AP frente a la opinión pública palestina? O, por el contrario, ¿fue la intifada una reacción callejera espontánea de palestinos encolerizados, pero desarticulados, ante la provocadora visita de Ariel Sharon a 
al Sharam al Sharif, los mismos palestinos que, adicionalmente, se sentían desengañados y decepcionados porque, tras varios años de proceso de paz, no se ha logrado poner fin a treinta y tres años de ocupación militar israelî?

Mientras la mayoría de los israelíes $\mathrm{y}$, en especial, los miembros de la comunidad de la inteligencia, invocan la primera tesis y explican todo lo que sucede en la intifada en función de ella, la AP y los palestinos se inclinan por la segunda.

\section{Sólo un proceso de paz realmente} viable y un compromiso de buen gobierno por parte de la AP pueden dar salida al actual predicamento.

El presente artículo ofrece una tercera tesis: sostiene que la intifada ha sido claramente una reacción articulada y organizada de la Joven Guardia del movimiento nacional palestino, no tan sólo a la visita de Sharon a al Sharam al Sharif $y$ al hecho de que el proceso de paz no haya logrado poner fin a la ocupación israelí, sino también a que la Vieja Guardia de la OLP no ha sido capaz de dirigir el proceso de independencia, construcción del Estado y gobernabilidad palestinos. Mediante la intifada, y bajo la influencia de los métodos de Hizbullah, la Joven Guardia trató de obligar a Israel a retirarse unilateralmente de Cisjordania y la Franja de Gaza y, al mismo tiempo, de debilitar y terminar por desplazar a la Vieja Guardia. En especial, la Joven Guardia concibió el recurso a la acción armada como un medio de liberación nacio- nal, a fin de lograr rápidamente ambos objetivos, no sólo pese a la superioridad del ejército israelí sino, también, pese a unas fuerzas armadas y servicios de seguridad de la AP mucho más fuertes.

A catorce meses de iniciada la intifada, la Joven Guardia está resuelta a hacerlo. Hasta ahora, ha logrado obligar a Israel a considerar seriamente la posibilidad de una separación unilateral, y debilitar considerablemente a la Vieja Guardia. Es más, ha logrado asumir el control de facto sobre la mayoría de las instituciones de la AP, infiltrar sus servicios de seguridad y obligar a Arafat a apaciguarla y obtener su aprobación ante el temor de perder su propia autoridad y tener que hacer frente a la posibilidad de una guerra civil palestina. No obstante que la forma en que evolucionen las relaciones israelo-palestinas influirá sobremanera en la dinámica interna, lo cierto es que lo único que puede darles a Israel y la AP una salida a su actual predicamento es la combinación de un proceso de paz realmente viable y un sincero compromiso de buen gobierno por parte de la AP.

\section{LAS DOS DINÁMICAS DE LA INTIFADA}

La intifada consolidó dos dinámicas muy significativas en la política y la sociedad palestinas. La primera se relaciona con la evolución al interior del movimiento nacional y, la segunda, con la rivalidad entre islamistas y nacionalistas. Las consecuencias de la primera, que entraña la división del movimiento entre la Vieja Guardia y la Joven Guardia, son 
inmediatas y de gran alcance y limitan apreciablemente la capacidad de los líderes de la AP para manejar las crisis actuales y comprometerse en un proceso político viable con Israel. La segunda, que entraña una modificación del equilibrio interno del poder en favor de los islamistas por primera vez en siete años, tarda mucho más en hacerse sentir, pero una vez arraigada difícilmente podrá revertirse, ya que implica un cambio ideológico y social.

A la larga, la segunda dinámica constituye un serio reto a la capacidad del movimiento nacional de seguir conduciendo al pueblo palestino. El hecho de que ni el proceso de paz ni el de reconstrucción nacional hayan estado a la altura de las expectativas de la mayoría o la totalidad de los palestinos, ha preparado la escena para estos acontecimientos. El presente trabajo trata de las ramificaciones de la primera dinámica para la AP y el proceso de paz.

\section{Procesos fallidos, PUeblo airado}

Los datos de esta sección se basan en más de 75 encuestas realizadas por el autor entre 1993 y 2001 en Cisjordania y la Franja de Gaza, incluido Jerusalem oriental árabe. El tamaño de cada muestra fluctuó entre 1300 y 2000 entrevistas personales ${ }^{1}$. La firma del Acuerdo de Oslo, en septiembre de 1993, concitó el inmediato apoyo de dos tercios de la opinión pública palestina. Los palestinos cifraron en él grandes esperanzas; se suponía que diera lugar a tres procesos: el fin de la ocupación, la adopción de un sistema político abierto, democrático y de una autoridad nacional y el rápido mejoramiento de la situación económica y de las condiciones de vida. Pero la bonanza del proceso de paz no duró mucho. Alcanzó su punto máximo entre 1995-1996, tras un desalentador 1994. En 1996, su respaldo llegó a un $80 \%$, mientras que el apoyo al uso de la violencia contra blancos israelíes se redujo a 20\%. En vísperas de las elecciones generales de enero de 1996, el apoyo a Al Fatah, principal movimiento nacional, alcanzó el nivel sin precedentes de $55 \%$, y la popularidad de Arafat se disparó a $65 \%$. A comienzos de ese año, los grupos de oposición islamistas y nacionalistas redujeron su tamaño a $20 \%$, en circunstancias de que dos años antes había sido de $40 \%$.

\section{La firma del Acuerdo de Oslo concitó el inmediato apoyo de dos tercios de la opinión pública palestina.}

El sistema político palestino creado tras las elecciones de enero de 1966, reunía los requisitos de legitimidad. Pese a los llamados a la abstención formulados por los grupos de oposición, un $75 \%$ de los electores con derecho a voto acudie-

${ }^{1}$ Para mayores detalles, consúltese la página web del Centro Palestino de Investigaciones y Política (www.prpsr.org). 
ron a las urnas. Arafat fue apoyado por más del $70 \%$, mientras que un $22 \%$ votó en blanco y sólo un $8 \%$ por su rival, la señora Samiha Khalil. Al Fatah obtuvo un increíble $77 \%$ de los asientos del nuevo Consejo Legislativo Palestino (CL.P).

Con la sola excepción de 1994, y pese a que la derecha ganó las elecciones israelíes de mediados de 1996, entre 1991 y 2001 el apoyo al Acuerdo de Oslo nunca bajó de 60\%. Sin embargo, a raíz de la elección de Benjamin Netanyahu como primer ministro de Israel y debido a que siguieron construyéndose asentamientos judíos en Cisjordania y la Franja de Gaza, los palestinos comenzaron a perder la confianza en el proceso de paz. Aunque nunca estuvieron demasiado seguros de que el proceso pondría pronto fin al arreglo de autonomía limitada, llevando al reconocimiento permanente de su condición de Estado, las esperanzas de los palestinos cayeron de $44 \%$, en la época de Shimon Peres, a $30 \%$ cuando asumió Netanyahu. Cuatro años después, cuando gobernaba Israel Ehud Barak y continuaba la expansión de los asentamientos judíos, las esperanzas de llegar a un acuerdo permanente se habían reducido a 24\%. Cuando Ariel Sharon fue elegido primer ministro, una baja de 55\% situó la cifra en un mero $11 \%$.

La pérdida de la confianza en que el proceso de paz llevaría a un acuerdo permanente repercutió de manera dramática en el apoyo prestado por el pueblo palestino a la violencia contra los israelíes. En julio de 2000, inmediatamente después de la cumbre de Camp David, pero en vísperas de la segunda intifada, este apoyo se había elevado a $52 \%$. Un año después, a diez meses de iniciada la intifada, alcanzó el nivel sin precedentes de $86 \%$.

\section{La pérdida de confianza en el proceso de paz repercutió dramáticamente en el apoyo del pueblo palestino a la violencia.}

Otros damnificados han sido la popularidad de Arafat y el apoyo a Al Fatah. En julio de 2000, a su regreso de Camp David, la popularidad de Arafat, que ha mermado sostenidamente desde 1996, se desplomó a un $47 \%$. Diez meses después del comienzo de la segunda intifada, tuvo su peor caída en ocho años, perdiendo $30 \%$ en un solo año, para situarse en 33\%. Por su parte, en julio de 2000 el apoyo a Al Fatah bajó a 37\%, lo que representa una caída de $33 \%$ en cuatro años. Un año después, perdió un $22 \%$ adicional, con lo que su apoyo se redujo al 29\%. Curiosamente, el apoyo a los islamistas no aumentó mucho entre 1996, cuando llegaba a $15 \%$, y 2000 , en que fue de $17 \%$. Los que abandonaron a los nacionalistas no adhirieron a los islamistas sino que optaron por no abanderizarse. La intifada cambió la situación: en julio de 2001, el apoyo a los islamistas ha aumentado un $60 \%$, llegando a $27 \%$. Por primera vez desde 1995, la intifada trajo consigo un cambio importante en el equilibrio interno del poder, ya que un número cada vez mayor de personas abandonó las filas nacionalistas para adherir a las islamistas. De hecho, en julio de 2001 y por primera vez, el apoyo a los grupos de oposición nacionalista e islamista, que en su conjunto lle- 
gaba a $31 \%$, superó el apoyo al movimiento principal Al Fatah y sus aliados, que era de $30 \%{ }^{2}$.

La merma del apoyo a Arafat obedece a otros factores además del colapso del proceso de paz y del deterioro de la situación económica y de las condiciones de vida. Al hombre de la calle le ha decepcionado que, al parecer, el proceso de reconstrucción nacional y de gobernabilidad haya fracasado. En los últimos seis años, la impresión que tiene sobre la democracia, los resultados obtenidos por la AP y los niveles de corrupción han ido de mal en peor. En 1996, un 43\% tenía una impresión favorable acerca de la democracia y los derechos humanos; en 20002001, ese porcentaje se había reducido en más de 50\%, acercándose al $21 \%$. Por 10 que respecta a los resultados obtenidos por la AP, las opiniones favorables bajaron de $64 \%$, en 1996 , a $44 \%$ en 2000 y a $40 \%$ en 2001 . Lo que es peor, mientras que en 1996 sólo un 49\% pensaba que había corrupción en las instituciones de la AP, la cifra se elevó a $76 \%$ en 2000 y a 83\% en 2001.

Durante la intifada, la creciente decepción de la opinión pública se ha agravado y ello ha mermado aún más la confianza en el proceso de paz y la disposición a extender el reconocimiento de legitimidad a la AP. El implacable asedio, la clausura de los territorios y las medidas de castigo colectivo impuestas por Israel han prácticamente paralizado la vida civil, social y económica palestinas, devastado la economía y aumentado la sensación de peligro y coerción, lo que no hace más que provocar pesimismo, odio ciego y deseos de matar. Tras el colapso de la cumbre de Camp David y transcurridos diez meses de la intifada, la confianza en que no habría violencia y en que pronto se reanudarían las negociaciones había cedido lugar a un pesimismo mucho más profundo y las expectativas habían disminuido de $44 \%$ a $17 \%$. Mientras que en julio de 2000 sólo un 23\% consideraba que el fracaso de Camp David marcaba el término del proceso de paz, en julio de 2001 esa proporción se había duplicado. Simultáneamente, mientras que en julio de 2000 sólo un $31 \%$ pensaba que el uso de la violencia contribuiría, más que las negociaciones, a que los palestinos alcanzaran sus objetivos, un año después la cifra se había elevado a $59 \%$. En efecto, en julio de 2001, una amplia mayoría de $71 \%$ pensaba que la intifada ya lo había logrado.

\section{Durante la intifada ha mermado aún más la confianza en el proceso de paz.}

La impresión de que el proceso de paz había fracasado, unida a una evaluación muy negativa de todo lo relacionado con la gobernabilidad de la AP, su persistente falta de competencia para proporcionar

\footnotetext{
${ }^{2}$ Para mayores detalles relativos al período 1993-1998, véase Shikaki, Khalil. "Peace Now or Hamas Later", Foreign Affairs, julio-agosto 1998, págs.29-43.
} 
servicios al grueso de la población en momentos de extraordinarias dificultades económicas y sociales y, lo que es peor, la impresión dominante de que Arafat no era capaz de proyectar liderazgo ante un futuro incierto, influyeron muy negativamente en la legitimidad de la AP y permitieron que surgieran y se impusieran otras fuentes de autoridad. Una de estas nuevas fuentes ha sido la "legitimidad revolucionaria" invocada por la Joven Guardia. Aprovechando la cólera popular provocada por la visita de Sharon a al Sharam al Sharify la posterior muerte de decenas de civiles palestinos en pocos días de confrontación popular, la Joven Guardia estaba lista para aprovechar la oportunidad.

\section{LA Joven GuARDia CONTRA \\ la VIEja Guardia}

Entre 1967 y 1994, los líderes de la vanguardia nacional palestina vivieron una diáspora, trasladándose de Jordania al Líbano, y desde 1983, a Túnez. Periódicamente, los líderes locales de Cisjordania y la Franja de Gaza trataron de imponerse, para pronto ser descabezados por los israelíes o desalentados por la OLP. La derrota de ésta durante la invasión del Líbano, en 1982, menoscabó el lugar central que ocupaba en la política palestina y debilitó la autoridad que ejercía sobre los palestinos que vivían en los territorios ocupados. En rigor, el centro de gravedad de la política palestina comenzó a desplazarse de fuera hacia adentro, esto es, a Cisjordania y la Franja de Gaza. Pese al importante papel que des- empeñaron los líderes externos de la OLP durante la primera intifada palestina, quienes la iniciaron y sostuvieron fueron los nuevos líderes de los territorios ocupados.

En 1994, los líderes de la OLP regresaron a Cisjordania y la Franja de Gaza para establecer la Autoridad Palestina (AP), en cumplimiento de la Declaración de Principios que negociaron la OLP e Israel en Oslo, en 1993. A partir de entonces, las relaciones entre ambos liderazgos, los antiguos y establecidos, por una parte, y los nuevos y emergentes, por la otra, no ha sido fácil. Debido al talante autoritario del liderazgo de la OLP, no siempre fructificaron los esfuerzos para cooptar e, incluso, acomodar a los jóvenes líderes de la primera intifada. Sin embargo, la euforia que acompañó la retirada parcial de Israel del territorio palestino ocupado, el hecho de que en 1996 se realizaran las primeras elecciones generales nacionales y la creación del primer gobierno palestino de la historia moderna dieron la impresión de armonía entre ambos grupos.

\section{El liderazgo de la OLP ha pasado la mayor parte de su vida en el extranjero.}

El liderazgo establecido de la OLP es de carácter histórico. Está integrado por los padres fundadores del movimiento nacional palestino, los líderes de las diversas organizaciones guerrilleras y la burocracia de la OLP. Dicho liderazgo ha pasado la mayor parte de su vida en el extranjero. La mayoría de sus miembros 
se sitúa por encima de los cincuenta años y domina todas las instituciones de la OLP: el Consejo Nacional Palestino, el Consejo Central y el Comité Ejecutivo. Asimismo, controla el órgano decisor más importante de la OLP, el Comité Central de Al Fatah, además del Gabinete de la AP. Pese a que las elecciones de este órgano sólo tuvieron lugar en Cisjordania y la Franja de Gaza, un tercio del Consejo Legislativo Palestino (CLP) proviene de este grupo. Miembros de él, tales como Mahmud Abbas (Abu Mazin), Ahmad Qurie (Abu Ala) y Nabil Sha'ath han dirigido todas las negociaciones con Israel. En el presente trabajo, este grupo se conoce como la Vieja Guardia.

Por lo que toca a la Joven Guardia, se compone tanto de los líderes que han surgido a nivel local como de los antiguos líderes de la primera intifada. Más bien jóvenes, su edad fluctúa en torno a los cuarenta años. Pese a que algunos son miembros del gabinete de la AP y del CLP, y otros son jefes o autoridades de los servicios de seguridad, el grupo en su conjunto carece de cohesión, de liderazgo y de atribuciones legales. Por cierto, para algunos palestinos ciertos líderes de la Joven Guardia más parecen gángsters o caudillos militares. Algunos de éstos, como Sami Abu Samhadaneh, de Rafah y Aatif Ebiat, de Belén, han sido objetivos israelíes para su asesinato por el ejército. De hecho, el segundo fue muerto en octubre de 2001. Otros líderes de la Joven Guardia, como Marwan Barghouti, en Ramalla y Husam Khader, en Naplus, son más respetados en sus comunidades. Pese a que la Joven Guardia no tiene mucha voz en las principales instituciones de la OLP, posee mucho más peso relativo en órganos de $\mathrm{Al}$ Fatah como el Tanzim, su Alto Comité y su Consejo Revolucionario.

La Vieja Guardia deriva su autoridad del legado de la OLP y del Acuerdo de Oslo. Además, su poder radica en el control que ejerce sobre los recursos financieros de la OLP y la AP, en el reconocimiento diplomático que le otorga la comunidad internacional y en el control que ejerce sobre los principales órganos e instituciones de la OLP y la AP, incluidas su burocracia y sus servicios de seguridad.

\section{La Vieja Guardia deriva su autoridad del legado de la OLP y del Acuerdo de Oslo.}

La Joven Guardia tiene como base una legitimidad anterior a Oslo. Su poder viene de su alianza con los islamistas, del abrumador descontento popular respecto de los procesos de paz y de reconstrucción nacional, y del apoyo de la opinión pública al uso de las armas contra las fuerzas de ocupación y los colonos israelíes. Este apoyo a la Joven Guardia neutraliza los instrumentos de coerción de la Vieja Guardia y, en algunas circunstancias, los vuelve casi irrelevantes. Si bien es cierto que el brazo armado de la Joven Guardia tal vez no sea muy grande, le basta para controlar a muchas de las desintegradas instituciones civiles de la AP y para disuadir los intentos de los servicios de seguridad de la AP por aplastarlos. 
Pese a que, en la práctica, muchas de las instituciones controladas por la Vieja Guardia han perdido importancia, la Joven Guardia no ha pretendido crear otras que rivalicen con ellas. Por el contrario, parece confíar en que controlará las instituciones nacionales existentes. Por esta razón, pese a que es abiertamente contraria a algunas de las medidas y decisiones adoptadas por esas instituciones, se ha abstenido de oponerse a ellas o de poner en duda su legitimidad.

\section{La Joven Guardia ha llamado a crear un gobierno de unidad nacional que incluya a islamistas calificados y otros grupos de oposición.}

La Vieja Guardia tiene un liderazgo de jerarquía bien definida, aunque de carácter autoritario. En su cúspide se encuentra Arafat, quien no requiere la aprobación de la Vieja Guardia, ni necesita demostrarle credibilidad. En realidad, la Vieja Guardia busca su aprobación y deriva de él su propia autoridad. Su supervivencia como grupo depende de la presencia y apoyo sostenidos de Arafat. La Joven Guardia también reconoce el liderazgo y la legitimidad de Arafat, pero no deriva de él la suya. En rigor, es Arafat quien debe demostrarle su credibilidad. Al permitir que la Joven Guardia trate de aliarse con los islamistas y se trabe en enfrentamientos armados con el ejército israelí, gana su aceptación y aprobación. Así, asumiendo los riesgos de la situación, permitió que unidades de la Guardia pre- sidencial y de los servicios de inteligencia participaran ocasionalmente en ataques a soldados y colonos israelíes cuando Israel comenzó a atacar a las fuerzas regulares de policía y de seguridad de la AP. La opción alternativa de Arafat para obtener la aprobación de la Joven Guardia es abrir el sistema político palestino a la participación y fomentar una verdadera transición a la democracia, lo que hasta ahora ha tratado de evitar.

La Joven Guardia pretende algo más de Arafat. Exige transparencia, rendición de cuentas, una campaña para terminar con la corrupción, una reforma política amplia y mayor participación de los servicios de seguridad en los enfrentamientos con Israel. Declaraciones formuladas por A1 Fatah y el Comité nacionalista-islamista pro intifada han hecho hincapié en la apremiante necesidad de combatir la corrupción. Se la considera un medio para promover una mayor participación popular en la intifada y para expulsar a todos los miembros de la Vieja Guardia acusados de corrupción. Además, la Joven Guardia ha llamado a crear un gobierno de unidad nacional que no sólo incluya a integrantes de sus filas, sino también a islamistas calificados y otros grupos de oposición. La Joven Guardia ha apoyado con energía las exigencias de buen gobierno, tanto internas como internacionales, incluidos el respeto al orden jurídico, la independencia del poder judicial, el aumento de las atribuciones del poder legislativo y el fortalecimiento y mayor eficiencia de las instituciones públicas.

Por lo que atañe al proceso de paz, tanto la Joven Guardia como la Vieja 
Guardia aspiran a un Estado independiente, a vivir en paz como vecinos del Estado de Israel, con Jerusalem oriental árabe como capital, y a una solución justa al problema de los refugiados. En el encendido clima que se vive actualmente, la mayoría de los miembros de la Joven Guardia son "halcones", pero quizás ello sea un reflejo de la tensionante y sostenida percepción de amenaza que provoca el cotidiano derramamiento de sangre. De hecho, algunos miembros del grupo, como Sari Nusseibeh, presidente de la Universidad Al Quds y representante de Arafat en Jerusalem oriental, son muy moderados y, en la práctica, contrarios a que la Joven Guardia recurra a las armas.

Por el momento, la Joven Guardia se opone categóricamente a un acuerdo de cese del fuego, que entrañaría medidas enérgicas contra los activistas nacionalistas e islamistas. Por lo tanto, ha rechazado públicamente tanto el informe Mitchell como el Plan Tenet. En realidad, quiere que Arafat "salga del armario", apoye abiertamente las metas y métodos de la intifada y ordene a los servicios de seguridad de la AP que participen en los enfrentamientos armados. Tal sería su prueba de credibilidad definitiva.

Por otra parte, la Vieja Guardia abriga grandes dudas sobre la eficacia de la violencia. En rigor, critica abiertamente la participación de algunas fuerzas de seguridad de la AP en los enfrentamientos. Por ahora, muchos miembros de esta Vieja Guardia están convencidos de que Arafat no puede, seriamente, enfrentar a la Joven Guardia, a menos que haya una razonable certeza de llegar a un acuerdo de paz con Israel. También hay quienes sostienen que, por razones pragmáticas, los servicios de seguridad oficiales deben intervenir de manera ocasional en la lucha contra Israel: cuando llegue el momento de poner fin a los enfrenta-mientos armados, serán los únicos que tendrán autoridad y resolución para hacer frente y detener a los que deseen continuar la lucha.

\section{La prueba de credibilidad definitiva de Arafat sería su abierto apoyo a las metas y métodos de la intifada.}

Algunos miembros de la Vieja Guardia que no pertenecen a la AP han tratado de distanciarse de aquellos que sí forman parte de ella y establecer un nuevo foro de movilización y reforma políticas. En enero de 2001, el presidente del CNP propugnó la creación de una "Organización Nacional para la Independencia" y exigió que la AP se abocara a los problemas de la corrupción y la ausencia de orden jurídico, que juzgara a los acusados de corrupción, respetara y cumpliera las resoluciones de los tribunales y conminó al gabinete a renunciar, a fin de formar otro y designar un primer ministro. La Joven Guardia no se apresuró a hacer suyo este llamado, por recelar de los motivos en que se inspiraba; más bien trató de fortalecerse y reafirmarse, aunque sin condenar abiertamente a la Vieja Guardia de la AP, sino derrotando al ejército israelí mediante el uso de las armas. 


\section{Algunos miembros de la Vieja Guardia han tratado de establecer un nuevo foro de movilización y reforma políticas.}

La Joven Guardia se diferencia de la Vieja por la forma en que concibe la victoria en la lucha contra la ocupación. La Vieja Guardia desea una solución negociada que satisfaga las necesidades vitales de los palestinos, resultado que no sólo pondría fin a la ocupación, sino que le permitiría mantenerse en el poder durante muchos años; por su parte, la Joven Guardia no concibe la victoria, en estos momentos, como un resultado negociado. La retirada o separación unilateral de Israel calzaría muy bien con su definición de victoria, puesto que sería equivalente al retiro israelí del sur del Líbano bajo la presión de Hezbolá. Esto haría irrelevante el liderazgo de la Vieja Guardia y elevaría a la Joven Guardia a una posición de autoridad. Sin embargo, de ser posible, la Joven Guardia no podría oponerse a una solución negociada apoyada por la mayoría de los palestinos, pero tiene conciencia de que sólo la Vieja Guardia puede negociar esta clase de acuerdo. La Joven Guardia no tiene capacidad para realizar negociaciones serias con los israelíes: está lejos de constituir un liderazgo nacional unificado, dotado de una visión bien articulada, y carece de conocimientos, experiencia y contactos con ellos.

Al comienzo de la intifada, la Vieja Guardia acogió con agrado el levantamiento popular, confiada en que fortale- cería su posición negociadora ante la provocación de Sharon. Sin embargo, nunca existió la certeza de que, una vez iniciada, sería capaz de detenerla o de oponérsele abiertamente. Para la Joven Guardia, la intifada fue un medio de oponerse a los intentos de la Vieja Guardia de poner fin a la ocupación mediante la negociación. El fracaso de Camp David reafirmó su convicción de que la única forma era mediante el enfrentamiento popular y armado. Aunque no se muestra abiertamente contraria al actual proceso diplomático, la Joven Guardia no confía en él. Por el contrario, espera que aumentando el costo de la ocupación, Israel podría verse obligado a retirar unilateralmente su ejército de las zonas palestinas, tal como lo hizo en el sur del Líbano.

Sobre estas bases, la Joven Guardia persiguió un segundo objetivo: asegurar su predominio en el período posterior a la intifada y a la ocupación. Entretanto, mediante la creación de milicias armadas, logró colmar el vacío de poder que dejó el desmoronamiento de las instituciones de la AP. Los servicios de seguridad de ésta, que están armados pero no participan en la confrontación con Israel, no podían desafiar a las milicias armadas que participan en los choques con las fuerzas israelíes y que gozan de gran apoyo popular.

Para aumentar la presión de la intifada sobre Israel y fortalecer su posición interna frente a la Vieja Guardia, la Joven Guardia se asoció a los islamistas y a otras fuerzas de oposición. Pese a la impresión de que los islamistas constituían un peligro a largo plazo, la Joven Guardia prefirió tenerlos de su lado y bajo su autori- 
dad, recordando que, en la primera intifada, ellos establecieron sus propias autoridades, instituciones y fuerzas de choque.

\section{La división entre Vieja y Joven Guardias no es lo único importante que separa a la política y la sociedad palestinas.}

Naturalmente, la división entre Vieja y Joven Guardias no es lo único importante que separa a la política y la sociedad palestinas. Ya se aludió a la división entre nacionalistas e islamistas. Pero, hay algo más que las aparta y ello es que muchos miembros influyentes de la Vieja y de la Joven Guardias siguen convencidos de que el éxito del proceso de paz de Oslo es fundamental para los intereses nacionales. Miembros de la Joven Guardia, en especial los que se desempeñan en las instituciones de la AP y la OLP, como Mohammad Dahlan, jefe de los servicios de seguridad preventiva de la Franja de Gaza y Jibril al Rojoub, máxima autoridad de los mismos servicios en Cisjordania (además de otros, como Sari Nusseibeh), son tan contrarios como la mayoría de los miembros de la Vieja Guardia a la violencia de la actual intifada. Pero, visto que políticamente se ha llegado a un punto muerto y dado el abrumador apoyo popular a los enfrentamientos armados, este grupo y las instituciones y servicios de seguridad de la AP que controla, siguen siendo poco importantes. En todo caso, como se examinará en la sección siguiente, algunos de sus miembros podrían desempeñar un papel muy decisivo en la determinación del futuro palestino.

\section{DINÁMICAS INTERNAS}

EN TRES ESCENARIOS

El futuro de la situación interna palestina puede examinarse de acuerdo con tres hipótesis posibles:

- continuación del statu quo,

- separación unilateral de Israel y

- solución negociada.

La primera hipótesis parte de la base de que Israel, la Joven Guardia, los islamistas y demás grupos que se oponen a la AP seguirán tomando la iniciativa de la violencia, pero que ésta, con o sin Arafat a la cabeza, seguirá actuando sólo de manera reactiva. No excluye la posibilidad de que en el curso del proceso se produzca una grave escalada de la violencia. La mantención del statu quo favorece los intereses de los islamistas.

De otra parte, una separación unilateral de Israel beneficiaría a la Joven Guardia. Esta segunda hipótesis parte de la base de que si el ejército israelí se retira de algunas zonas de Cisjordania y de la Franja de Gaza, es posible que su retirada se acompañe de la evacuación de varios asentamientos y puestos exteriores aislados y escasamente poblados. La hipótesis se funda en que Arafat conserva su actual autoridad, pero no excluye la posibilidad de que pueda no encontrarse materialmente presente.

La tercera hipótesis parte de la base de que se haya llegado a algún tipo de solución negociada, provisional o perma- 
nente, con Arafat. Sin duda alguna, esta última hipótesis sería favorable a los intereses de la Vieja Guardia.

Lo más probable es que la continuación del statu quo permita que la dinámica actual avance sin tropiezos. En este caso, el apoyo de los palestinos al proceso de paz y las concesiones que entraña seguirá disminuyendo, mientras seguirá registrándose un marcado apoyo a la violencia. La AP seguirá perdiendo legitimidad y, junto con ello, caerá la popularidad de Arafat. El conflicto entre la Joven y la Vieja Guardias continuará debilitando el movimiento nacional $\mathrm{y}$, junto con aumentar la autonomía y el peso relativo de la Joven Guardia, la influencia de la Vieja Guardia irá desapareciendo gradualmente.

Lo más probable es que, al no existir un liderazgo alternativo, Arafat asuma la plena conducción de la Joven Guardia, pese a lo cual tendrá escaso margen de maniobra. $\mathrm{El}$ hecho de que no se encuentre presente puede acelerar la desaparición de la Vieja Guardia y dar lugar a que en la Joven Guardia aumenten las luchas internas para disputarse el liderazgo. Líderes de la Joven Guardia como Dahlan y Rojoub, integrados en la AP, seguramente se unirán a otros miembros de esa guardia, quienes les proporcionarán la muy necesaria infantería, mayor apoyo público y, más que nada, respetabilidad política. Entretanto, en el plano interno, esté o no presente Arafat, el equilibrio general de poder seguirá inclinándose hacia los islamistas, que en pocos años probablemente llegarán a ser la fuerza principal y contarán con el apoyo de la mayoría de los palestinos. A decir verdad, con toda probabilidad se intensificará la actual inclinación ideológica y societal hacia el islam conservador y político.

Esté o no esté presente Arafat, el equilibrio general de poder seguirá inclinándose hacia los islamistas.

La separación unilateral de Israel calza a la perfección con la idea de victoria de la Joven Guardia. Si no se produce una solución negociada, Israel seguirá buscando una alternativa al statu quo. Es posible que algunos israelíes se sientan atraídos por la idea de una separación unilateral, debido a que no exige contraparte. A medida que un número cada vez mayor de israelíes llegue a la conclusión de que los palestinos no pueden o no quieren aceptar la solución de compromiso ofrecida por sus gobiernos, se convencerán de que la separación es la salida para reducir las vulnerabilidades del país. Actualmente, la mayoría de los israelíes apoya la idea de levantar un muro de separación y el grado de apoyo dependerá de la medida en que el ejército israelí se retire de las zonas palestinas y del número de asentamientos que haya que evacuar. Mientras mayores sean la retirada y la evacuación, menor será el apoyo. Sin embargo, el apoyo suficiente de la mayoría o totalidad de los grupos que forman el espectro político proporciona una base realista para este escenario.

Para la Joven Guardia, la retirada obligada de Israel de las zonas palestinas equivaldría a su retirada del sur del Líba- 
no. La AP seguramente reaccionará como lo hizo el gobierno libanés y la Joven Guardia tal vez lo haga como Hezbolá. Dicho de otra manera, no hay grandes probabilidades de que la AP asuma el control del territorio y de los asentamientos recién evacuados. La Joven Guardia y los islamistas seguramente los declararán zonas liberadas y los utilizarán como bases para continuar su guerra en las zonas que sigan ocupadas. Lo más probable es que la alianza entre la Joven Guardia y los islamistas se fortalezca.

Con toda probabilidad la Joven Guardia arruinará las posibilidades de que la Vieja Guardia aproveche la retirada de Israel para reanudar las negociaciones. Seguramente utilizará su "victoria" para desafiar abiertamente e incluso, quizá, para desplazar a la Vieja Guardia, consolidando su liderazgo del movimiento nacional. Arafat seguirá siendo la única persona capaz de liderar la Joven Guardia, hasta que surja un liderazgo alternativo, con credenciales más nacionales que locales. Su ausencia aceleraría la búsqueda de líderes nacionales nuevos dentro de la Joven Guardia, sin que esto se manifieste en luchas internas. Éste sería particularmente el caso si, como se prevé, los miembros más antiguos de la Joven Guardia, que actualmente pertenecen a la AP, se alían con los más nuevos. Es posible que no sólo los directores de los servicios de seguridad, antes aludidos, sino también los miembros de la Joven Guardia que ocupan cargos de autoridad se suban al carro triunfal. Interpretada como un triunfo por la Joven Guardia, la retirada unilateral de Israel aumentará de ma- nera espectacular el apoyo popular al movimiento nacional y, en consecuencia, obstaculizará los esfuerzos de los islamistas por asegurar la hegemonía.

Sólo con la Vieja Guardia se puede lograr una solución negociada. Para ésta sería un salvavidas. La Joven Guardia no podría lograrla, aunque lo quisiera: carece de líder, su percepción general no es clara y no ha tratado antes con los israelíes. En todo caso, sería casi inconcebible que la Joven Guardia, tan crítica de la manera en que la Vieja Guardia ha manejado las negociaciones con Israel, acepte algo que ésta no pudo aceptar en Camp David y luego en Taba.

\section{Hasta que surja un liderazgo alternativo, Arafat seguirá siendo el único capaz de liderar la Joven Guardia.}

En esta situación hipotética, la Vieja Guardia reafirmaría su liderazgo, llegando a un acuerdo apoyado por la mayor parte de la opinión pública palestina. Lo más probable es que la Joven Guardia, aliada con los islamistas, trate de hacer fracasar cualesquiera esfuerzos negociados, pero el apoyo popular a un acuerdo seguramente haría inútiles sus intentos de oponerse. Lo que es más importante, en este caso es probable que los jefes de los servicios de seguridad de la Joven Guardia que pertenecen a la AP apoyen a la Vieja Guardia, con lo cual inclinarían la balanza contra cualquier discrepancia violenta. Un acuerdo negociado con Israel, particularmente si se acompaña de un 
proceso de reforma política interna, puede prolongar la vida al liderazgo de la Vieja Guardia. También puede abrir camino a intentos más pacíficos y quizás más fructíferos por reintegrar ambas ramas del movimiento nacional, mermando el atractivo que ejercen los islamistas.

\section{¿QUÉ SOLUCIÓN NEGOCIADA?}

¿Puede llegarse a una solución negociada? Las opciones posibles son tres: un acuerdo amplio, un conjunto de medidas de estabilización, y un arreglo de transición a mediano plazo.

Actualmente, ninguna de las tres parece posible: sin embargo, con alguna percepción y liderazgo de parte de los Estados Unidos y de Europa, sin duda podría convencerse a Arafat, e incluso a Sharon, que se allanen a aplicar un conjunto de medidas de estabilización como el que se indica a continuación.

\section{El acuerdo amplio}

La conclusión de un acuerdo amplio resolvería todos los puntos de discrepancia, incluso las cuestiones de Jerusalem y los refugiados, y pondría fin al conflicto. Como lo han puesto de manifiesto las diversas rondas de negociaciones israelopalestinas realizadas a partir de Camp David, tal acuerdo es factible. Siempre y cuando ambas partes vuelvan a sostener negociaciones serias, lo más probable es que traten de completar la labor comenzada con la iniciativa de Clinton en diciembre de 2000 y desarrollada en Taba en enero de 2001.

\section{La conclusión de un acuerdo amplio resolvería todos los puntos de conflicto.}

Para que materialice esta opción deben reunirse tres requisitos, ninguno de los cuales se da actualmente. Ellos son: que en Israel se produzca un cambio de gobierno que traiga consigo autoridades y una coalición menos comprometidos con la ideología del Gran Israel, que los Estados Unidos ejerzan un liderazgo resuelto y comprometido, decidido a lograr el éxito del proceso, y unidad de propósito entre la Vieja y la Joven Guardias, en la comunidad y los líderes palestinos.

Este último requisito podría darse mediante una reforma política interna que procure abrir el sistema político y crear una asociación viable entre ambos grupos. Por otra parte, la opinión pública israelí y palestina dudan mucho de que las partes sean capaces de llegar a un acuerdo de esta naturaleza. A decir verdad, en la situación actual en que se percibe un aumento de la amenaza, ninguna de las dos partes está dispuesta a apoyar las dolorosas concesiones que exige el éxito de un proceso de plena reconciliación. Esto no debería provocar desaliento sino, más bien, llevar a la conclusión de que sólo un liderazgo vigoroso, con una fuerte percepción de legitimidad, podría atreverse a seguir este camino. Una vez logrado el acuerdo, pero ni un minuto antes, lo más probable es que ambas partes apoyen estas concesiones.

Para los palestinos, sólo se podrá 1legar a un acuerdo amplio si el proceso es 
conducido por la Vieja Guardia, pero con la anuencia de los líderes emergentes de la Joven Guardia. En la situación actual, en que no hay reforma política, esto es poco probable. Para los israelíes, esta clase de acuerdo puede lograrse con un gobierno que prefiriera la democracia israelí, unida a un Estado de carácter judío, al control territorial de un "Israel más grande", pero logrado manteniendo la ocupación. Dada la coalición que gobierna actualmente Israel, dicha situación es en extremo improbable.

\section{La estabilización}

Lo único que se puede lograr con la aplicación de un conjunto de medidas estabilizadoras es una solución de parche, destinada a crear las condiciones necesarias para reducir la mutua percepción de amenaza, restablecer la confianza pública en el proceso de paz y facilitar el regreso a negociaciones más promisorias respecto al estatus definitivo. Dicho conjunto incluiría los siguientes elementos: el cese de todas las formas de violencia, el regreso al despliegue militar anterior a la intifada, la suspensión de la construcción de asentamientos, el cumplimiento de los compromisos de carácter provisional existentes -en especial el redespliegue real de los israelíes de la zona "C", acompañado del cumplimiento por la AP de sus propios compromisos transitorios-y el regreso a negociaciones para un régimen jurídico definitivo. La opinión pública de ambas partes está dispuesta a prestar apoyo a un conjunto de medidas estabilizadoras de esta naturaleza, ya que puede describirse y presentarse razonablemen- te como una forma más constructiva de cumplir los acuerdos existentes.

\section{Un acuerdo sobre medidas estabilizadoras no exige que el gobierno israelí renuncie a su ideal de un Israel más grande.}

Para suscribir con éxito un acuerdo sobre medidas estabilizadoras, podría contarse con la anuencia del actual gobierno israelí, puesto que no exige que renuncie definitivamente a su "Israel más grande". Sería necesario que la comunidad internacional, incluidos los Estados Unidos, interviniera más activamente, 10 que se ha facilitado después del 11 de septiembre de 2001. Del lado palestino, para que pueda aplicarse con éxito un conjunto de medidas estabilizadoras sería fundamental integrar plenamente a la Joven Guardia en el sistema político y sus órganos decisorios. De no existir tal integración, la Vieja Guardia tendría que imponer un impopular cese del fuego que podría despertar vigorosa y violenta resistencia en la Joven Guardia y en los brazos armados de los grupos de oposición islamistas y nacionalistas. Salvo que primero fructifique un acuerdo amplio, lo más probable es que en todos estos casos subsistan manifestaciones menores de violencia que amenacen con envenenar el ambiente y a la larga destruir el proceso de estabilización.

Para construir confianza, el proceso de estabilización requiere un monitoreo multinacional. Éste haría difícil que la Joven Guardia atacara blancos israelíes 
sin desafiar y poner en apuros abiertamente a Arafat. En consecuencia, el despliegue de supervisores aumenta el costo de la violación del cese del fuego, así como las posibilidades de que sea autoimpuesto. A decir verdad, si se responsabiliza de su fracaso a los que no cumplan las condiciones del acuerdo, la supervisión disuade su violación y asegura que sea cumplido por ambas partes. Además, cuando los supervisores tienen acceso al terreno y a la información, cada una de las partes puede verificar las intenciones de la otra. Por último, la supervisión puede ser un medio independiente de activar el cumplimiento de las diversas etapas del acuerdo y de esta manera estimula a cada parte a respetar sus disposiciones.

\section{Para construir confianza, el proceso de estabilización exige} un monitoreo multinacional.

Sin embargo, mientras ambas partes tengan legítimos motivos de queja que no puedan abordarse sólo con buenas intenciones la supervisión no puede resolver el problema del "impasse". Los motivos de queja pueden hacer que una o ambas partes suspendan el cumplimiento de sus compromisos e, incluso, actúen en forma contraria a lo previsto por las disposiciones del acuerdo. Como manera de resolver parcialmente la cuestión del "impasse", se puede aumentar la importancia de la función supervisora, agregándole un papel político, en virtud del cual funcionarios de alta jerarquía de los países involucrados en el proceso de supervisión pueden re- unirse periódicamente, a fin de evaluar el cumplimiento y las negociaciones.

Para los palestinos, al igual que en la primera opción, la Vieja Guardia es la única que puede llevar el proceso de negociaciones hacia la estabilización. Sin embargo, lo más probable es que la Joven Guardia trate de impedirlo si estima que es una manera de restablecer y consolidar el control ejercido por la Vieja Guardia. De más está decir que la Joven Guardia ya ha logrado imponer un control de facto sobre muchas, si no la mayoría, de las instituciones civiles de la AP y, conjuntamente con los islamistas, ha penetrado de manera importante en los servicios de seguridad de la AP.

Para los israelíes, la estabilización exigirá adoptar medidas que de seguro afectarán a los asentamientos judíos. Si la construcción de éstos se paraliza totalmente, su viabilidad se verá seriamente amenazada, puesto que obstaculizará los esfuerzos de los colonos por crear hechos consumados y mantener viva la opción del "Israel más grande", en su avance hacia un asentamiento permanente. Además, cuando de acuerdo con esta opción el ejército israelí lleve a cabo un tercer redespliegue desde la zona "C" en Cisjordania, la empresa de los asentamientos sufrirá un serio retroceso. La verdad es que para que un tercer redespliegue sea pleno y verosímil habría que evacuar muchos asentamientos y puestos exteriores pequeños y aislados, la mayoría de los cuales fueron construidos o habitados después del acuerdo de Oslo de 1993. Los colonos y los derechistas que los apoyan en la actual coalición de gobierno seguramen- 
te se opondrán a esta evacuación. Pese a que esto no significa la caída del gobierno de Sharon, no hay duda de que debilitará el apoyo que le presta la derecha.

\section{Un acuerdo de transición}

\section{a mediano plazo}

La opción de estabilización es susceptible de mejorarse convirtiéndola en un arreglo de transición a mediano plazo. Es posible que Sharon se refiera a esta opción como un "acuerdo provisional a largo plazo". Para Arafat podría ser un mecanismo nuevo y mejorado para el cumplimiento del acuerdo provisional existente. Presentado en la forma adecuada, tanto israelíes como palestinos podrían comprar un paquete estabilizador enriquecido.

\section{Para Arafat, un arreglo de transición a mediano plazo podría ser un mecanismo nuevo para el cumplimiento del acuerdo provisional existente.}

De acuerdo con esta opción, se agregarían cuatro elementos adicionales a los ya mencionados: la evacuación israelí de la totalidad de la Franja de Gaza, incluida la eliminación de todos los asentamientos; la aplicación de nuevas medidas de redespliegue israelí en Cisjordania, que aseguren la plena contigüidad del territorio palestino; la creación de un Estado palestino en Cisjordania y la Franja de Gaza, y la ampliación del mandato de los supervisores internacionales, de manera que comprenda la vigilancia de las fuer- zas israelíes y el control palestino de los pasos fronterizos internacionales. El ministro de Relaciones Exteriores de Israel ya se ha mostrado partidario de la mayoría de estos elementos. De acuerdo con las informaciones, Sharon ha estado dispuesto a discutir la evacuación de Gaza. Como primer ministro ha expresado reiteradamente su disposición a aceptar la creación de un Estado palestino cuyo territorio tenga contigüidad.

\section{Conclusión}

Los dramáticos sucesos del 11 de septiembre tuvieron un importante aunque transitorio efecto en la situación interna palestina. La indignación y el rechazo internacionales del terrorismo y la decisión de los Estados Unidos y otros países occidentales de crear una alianza mundial para combatirlo, provocaron ciertos temores y brindaron oportunidades a los palestinos. Arafat estuvo resuelto a evitar cualquier asociación con el terrorismo contra civiles y deseoso de mostrar su solidaridad con los Estados Unidos. La mayoría de los palestinos, incluida la Joven Guardia, temió que Israel aprovechara la tragedia para lanzar un devastador ataque contra las zonas controladas por la AP. Además, los islamistas palestinos temieron que se les relacionara, ya sea en su organización o en los objetivos y métodos, con el grupo terrorista responsable de los ataques contra los Estados Unidos. Dicha asociación los habría convertido en blanco inmediato de las represalias estadounidenses. En consecuencia, inmedia- 
tamente después del atentado no era oportuno lanzar ataques suicidas contra civiles israelíes. Para la Joven Guardia, la alianza con los islamistas amenazó con convertirse en un inconveniente, mientras que las credenciales internacionales de Arafat y la Vieja Guardia pasaron a ser codiciada ventaja y resguardo. Para Arafat, el costo del permanente apaciguamiento de la Joven Guardia se multiplicó. Con la atención internacional dirigida a otro lugar, incluso temió por su vida.

Por otra parte, la necesidad del apoyo árabe e islámico a la guerra estadounidense contra el terrorismo ofreció nuevas posibilidades. Fue sólo después de una situación similar, durante la guerra del Golfo de 1990-1991, cuando un gobierno estadounidense ejerció suficiente presión sobre el gobierno derechista de Yitzhak Shamir, para que participara en la conferencia internacional de paz de Madrid. Arafat y la Vieja Guardia confiaron en que esta vez sucedería algo semejante. De hecho, se valieron de presiones y persuasión sobre los miembros de la Joven Guardia, quienes se mostraron dispuestos a aceptar una calma transitoria. Incluso los islamistas estuvieron de acuerdo. Además de que querían negarle a Sharon la posibilidad de atacarlos impunemente, los dos grupos aliados dudaban de que pudiese darse un avance político y estaban convencidos de que Sharon no estaría dispuesto a seguirle la corriente a los Estados Unidos, como lo había estado Shamir.

Hasta ahora, han demostrado tener la razón. Comprometidos con un postulado en cuya virtud tras todo incidente violento estaba la mano de Arafat, Sharon y los miembros de mayor jerarquía del ejército y de los servicios de inteligencia israelíes parecen haber llegado ya a la conclusión de que aquél ya no era un interlocutor válido. A decir verdad, es posible que se hayan comprometido, concienzuda y gradualmente, en un proceso para deslegitimarlo y privarlo de su autoridad. Han comprendido que la calma relativa era cosa transitoria. Más importante aún, partieron de la base de que la diplomacia posterior al 11 de septiembre podía ser un salvavidas para Arafat, y estuvieron resueltos a impedir que lo agarrara. La política israelí de asesinatos e incursiones en la Zona A se mantuvo, pese a que en un breve tiempo Arafat había logrado disminuir el nivel de la violencia en más de un $80 \%$. En definitiva, el círculo vicioso de la violencia encontró manera de esquivar las oportunidades que brindaba el 11 de septiembre. Incapaz de obligar a Arafat a adherir firmemente al cese del fuego o poner coto a las permanentes provocaciones de Sharon, la diplomacia internacional no estuvo a la altura del desafío.

Por ahora, Arafat y la Vieja Guardia seguirán siendo incapaces de comprometerse a cumplir cabalmente con el cese del fuego. Desde el inicio de la segunda intifada no tienen la capacidad para imponerlo y deben equilibrarse en la cuerda floja: la AP ya no tiene el monopolio del uso de la fuerza, la opinión pública cuestiona su legitimidad y, además, apoya vigorosamente la violencia y se opone con energía a apretarles las clavijas a los islamistas o a la Joven Guardia. A mayor abundamiento, no se divisa la posibilidad de un proceso político viable. Si Arafat 
actúa ahora contra los islamistas y la $J o-$ ven Guardia, y tiene éxito, corre el riesgo de que los palestinos lo consideren un lacayo de los israelíes o, incluso, un "Sa'd Haddad", nombre del comandante libanés del ejército del sur del Líbano creado por Israel, a fines de los 70 para proporcionar seguridad al norte de Israel. Si fracasa, hay posibilidades de que se produzca la guerra civil. En consecuencia, sus opciones son limitadas. Si varía el entorno político, de modo que Arafat obtenga legitimidad y cuente con el apoyo de la opinión pública, puede arriesgarse a imponer un cese del fuego. Un proceso político viable, iniciado y conducido por los Estados Unidos y apoyado por la comunidad internacional, puede contribuir a producir el cambio requerido. Pese al 11 de septiembre, actualmente hay escasas posibilidades de que se produzca un esfuerzo internacional de esta envergadura.

Si la actual situación es mala, hay que imaginar cómo sería sin Arafat. En estos momentos, es el factor cohesionante que mantiene unidas a la Vieja y a la Joven Guardias e impide que la primera asuma el poder en forma total e inmediata. Pese a la pobreza de sus habilidades como comunicador, Arafat sigue dándole al pueblo palestino una sensación de estabilidad que impide que se produzcan grandes violaciones de la ley y el orden. Su presencia disuade a los islamistas en cuanto peligro inmediato para el vacilante dominio de los nacionalistas. Si él falta, el infierno podría ser incontrolable. Arafat y la AP tienen una alternativa a este sombrío futuro: en vez de esperar un plan de paz estadounidense-internacional, pueden iniciar ahora un proceso de reforma política. Si lo hacen, Arafat y el movimiento nacional pueden recuperar el apoyo de la mayoría de los palestinos y, al mismo tiempo, integrar a la Joven Guardia en la AP. En verdad, para Arafat, la Vieja Guardia y todos los palestinos, el mensaje es claro: reformarse o morir. 